\title{
Association between subchronic and chronic lead exposure and levels of antioxidants and chemokines
}

\author{
Michał Dobrakowski ${ }^{1}$ - Aleksandra Kasperczyk ${ }^{1} \cdot$ Natalia Pawlas $^{2} \cdot$ Ewa Birkner $^{1}$ • \\ Edyta Hudziec $^{1}$ - Ewa Chwalińska ${ }^{1} \cdot$ Sławomir Kasperczyk $^{1}$
}

Received: 11 February 2016 / Accepted: 6 June 2016 / Published online: 13 June 2016

(C) The Author(s) 2016. This article is published with open access at Springerlink.com

\begin{abstract}
Purpose This study aimed to compare the influence of lead on the non-enzymatic antioxidant defenses and the levels of chemokines in workers subchronically and chronically exposed to lead.

Methods The study population was divided into three groups. The first group consisted of male workers subchronically exposed to lead for $40 \pm 3.2$ days, while the second group included male workers chronically exposed to lead. The third group was a control group.

Results The levels of uric acid and bilirubin were significantly higher after a subchronic exposure to lead compared to the baseline by 22 and $35 \%$, respectively. Similarly, the values of total antioxidant capacity (TAC), total oxidant status (TOS), and oxidative stress index (OSI) increased by 15,50 , and $33 \%$, respectively. At the same time, the levels of thiol groups and albumin decreased by 5 and $8 \%$, respectively. Additionally, the levels of interleukin-8 (IL-8) and macrophage inflammatory protein- $1 \beta$ (MIP-1 $\beta$ ) were significantly higher after a subchronic exposure to lead compared to the baseline by 34 and $20 \%$, respectively. Moreover, IL-8 level was significantly higher by $40 \%$ in the group of workers chronically exposed to lead than in the control group, while the level of interferon gamma-induced protein-10 (IP-10) was significantly lower by $28 \%$.
\end{abstract}

Michał Dobrakowski

michal.dobrakowski@poczta.fm

1 Department of Biochemistry, School of Medicine with the Division of Dentistry, Medical University of Silesia, ul. Jordana 19, 41-808 Zabrze, Poland

2 Institute of Occupational Medicine and Environmental Health in Sosnowiec, ul. Kościelna 13, 41-200 Sosnowiec, Poland
Conclusions Similar to chronic lead exposure, subchronic exposure to lead is associated with elevated blood levels of uric acid and bilirubin in humans. This probably results in increased TAC value despite thiol depletion. However, the compensatory activation of non-enzymatic antioxidant defenses seems to be insufficient to protect against leadinduced oxidative stress, which may be additively enhanced by the pro-inflammatory action of chemokines, especially IL-8.

Keywords Subchronic exposure to lead Chronic exposure to lead · Non-enzymatic antioxidants · Uric acid . Chemokines

\section{Introduction}

Lead is a heavy metal, which has been widely used for decades in paint, gasoline, water pipes, storage batteries, and many other products (Lin et al. 2015). In the last decades, our view on lead toxicity has changed, giving more concern to exposures, previously considered safe. Lead can induce many adverse health effects on various body systems including the nervous, hematological, immune, and genitourinary systems. Nevertheless, due to its malleability, resistance to corrosion, and low melting point, lead is still widely used in many industries (Wang et al. 2012).

Ingestion and inhalation are the primary routes of lead entering the body. After absorption, lead is distributed through the bloodstream to various organs, such as brain, liver, and kidneys (Alya et al. 2015). It has been proposed that kidneys play an important role in the toxicokinetics of lead because they serve as the major organ responsible for its excretion. Therefore, kidneys are particularly exposed to lead toxicity. Lead primarily impairs the function and 
structure of the renal tubules. Renal tubular epithelial cell necrosis, leukocyte infiltration, and tubular epithelial cell pyknosis have been shown to be induced by lead toxicity. Many studies indicated that long-term exposure to lead increases the risk of nephropathy, which manifests as increased levels of renal dysfunction biomarkers, such as plasma creatinine and uric acid (Alya et al. 2015; Liu et al. 2012).

Several mechanisms have been proposed to explain lead-induced toxicity. One of them implicated oxidative stress as the underlying mechanism of toxicity (Wang et al. 2012). Oxidative stress results from imbalance between the generation and utilization of reactive oxygen species (ROS). Lead ions have been shown to be associated with increased generation of ROS. Besides, lead is able to dysregulate the antioxidant defenses, including the antioxidant enzymes and the non-enzymatic antioxidants, such as uric acid. (Dobrakowski et al. 2014; Soliman et al. 2015; Wang et al. 2012). In our previous study, we reported higher levels of uric acid in workers chronically exposed to lead compounds (Blood lead $(\mathrm{PbB})=40.40 \pm 10.05 \mu \mathrm{g} / \mathrm{dl}$ ) for, on average, $16.40 \pm 10.20$ years compared to the unexposed control group $(\mathrm{PbB}=6.39 \pm 2.47 \mu \mathrm{g} / \mathrm{dl})$. Besides, we reported increased levels of other non-enzymatic antioxidants, such as bilirubin, albumin, thiol groups, and $\alpha$-tocopherol (Dobrakowski et al. 2014). However, the possible association between lead toxicity and the nonenzymatic antioxidant defenses is not fully understood and needs further investigation.

Negative effects of lead on human health may be also due to its impact on the immune system function. It has been shown that lead impairs the function of lymphocytes and cytokine production. Some studies indicate lead-induced shift in the balance of T-helper (Th) lymphocyte function toward Th2-mediated immune response at the expense of Th1-mediated response (García-Lestón et al. 2012; Hsiao et al. 2011). Besides, lead exerts proinflammatory properties. In experimental and human studies, lead exposure has been shown to induce expression of pro-inflammatory cytokines, such as tumor necrosis factor- $\alpha$ (TNF- $\alpha$ ), interleukin-6 (IL-6), and interleukin- $1 \beta$ (IL-1 $\beta$ ) via activation of mitogen-activated protein kinases (MAPKs) and nuclear factor kappa B (NF-кB) (Liu et al. 2012). Both MAPKs and NF- $\mathrm{B}$ can be induced synergistically by uric acid (Kanellis et al. 2003; Liang et al. 2015). Moreover, uric acid exerts its pro-inflammatory action via increasing the levels of chemokines, such as interleukin-8 (IL-8), monocyte chemoattractant protein-1 (MCP-1), and RANTES (regulated on activation, normal T cell expressed and secreted) (Liang et al. 2015; Zhou et al. 2012). Similarly, lead has been shown to induce interleukin-8 (IL-8), a potent chemokine (Lin et al. 2015; Yang et al. 2014).
Up-to-date studies indicate lead-induced dysregulation of the immune response in humans. However, in the available literature, there are no conclusive epidemiological studies regarding the immunotoxic effects of lead in occupationally exposed workers. Similarly to mechanisms underlying the associations between lead and the non-enzymatic antioxidant defense, the exact mechanisms of lead interactions with the immune system in humans still remain unclear (García-Lestón et al. 2012). Some authors postulate that the influence of lead on the immune response is dosedependent (Hsiao et al. 2011; Iavicoli et al. 2006). Duration of exposure seems to be the second factor modifying interactions of lead with the immune system. In light of this, we decided to examine workers subchronically and chronically exposed to lead. We focused on the influence of lead on the non-enzymatic antioxidant defenses, including uric acid, and chemokine levels, which may be related to the immunomodulatory properties of both lead and uric acid.

\section{Materials and methods}

\section{Study population}

Each study subject provided a written consent to a study. Questionnaire data on age, weight, height, medical history, and smoking were obtained. The levels of lead and zinc protoporphyrin in the blood served as biomarkers of lead exposure.

The study population was divided into three groups. The first group consisted of 34 male workers subchronically exposed to lead for 36-44 days, aged from 22 to 61 years. Subjects in this group worked in lead-zinc works to perform periodic maintenance of blast furnaces and production lines. Among the exposed population, 17 workers were occupationally exposed to lead for the first time, while the other 17 workers had a history of occupational exposure to this xenobiotic. Workers were subjected to high doses of lead because they did not adhere to the occupational safety and health precautions and did not properly use personal protective equipment.

The second group included 52 male workers chronically exposed to lead for a maximum of 38 years, aged from 23 to 55 years. Workers in that group worked in lead-zinc works as smelters, fitters, and production masters.

The third group was a control group, which included 22 male administrative employees aged from 26 to 59 years. Their blood lead levels were below $10 \mu \mathrm{g} / \mathrm{dl}$. None of the subjects in this group was occupationally exposed to lead.

Exclusion criteria included history of any chronic diseases (such as immune disorders, diabetes, arterial hypertension, coronary artery disease, and malignant neoplasm) 
and abnormal physical examination findings, especially symptoms and signs of any infectious diseases.

The experimental setup has been approved by the Bioethics Committee of the Medical University of Silesia in Katowice No. KNW/0022/KB1/108/14.

\section{Laboratory procedures}

\section{Blood collection}

Blood was drawn once from workers chronically exposed to lead and from subjects in the control group. However, blood was drawn twice from workers subchronically exposed to lead, at the beginning of the study and after a period of subchronic exposure to lead.

Blood samples obtained from each subject were taken from the cubital vein using vacuum tubes (Vacuette ${ }^{\circledR}$; Greiner-Bio, Frickenhausen, Germany) that contained K3EDTA to obtain whole blood or using plain tubes to obtain serum. Blood samples were frozen and stored at $-20{ }^{\circ} \mathrm{C}$ until used.

\section{Determination of lead concentration}

$\mathrm{PbB}$ assessments were performed by graphite furnace atomic absorption spectrometry using ICE 3400 instrument (Thermo Fisher Scientific Waltham, MA, USA). The laboratory met the requirements of proficiency tests (Lead and Multielement Proficiency-CDC in Atlanta). Clin$\mathrm{Cal}^{\circledR}$ Whole Blood Calibrator and ClinCal ${ }^{\circledR}$ Serum Calibrator (Recipe, Germany) were used for calibration of the instrument and control materials. ClinCheck Whole Blood Control Levels I, II, and III, and ClinCheck Serum Control Levels I and II were used for quality control. Data were expressed as $\mu \mathrm{g} / \mathrm{dl}$.

\section{Determination of zinc protoporphyrin concentration}

The blood concentration of zinc protoporphyrin (ZPP) was measured directly using Aviv Biomedical hematofluorometer model 206, using an excitation wavelength of $415 \mathrm{~nm}$ and an emission wavelength of $596 \mathrm{~nm}$. The instrument measures the ratio of ZPP fluorescence to the sample (hemoglobin) absorption, displayed as $\mu \mathrm{g}$ ZPP per $\mathrm{g}$ of hemoglobin $(\mu \mathrm{g} / \mathrm{g} \mathrm{Hb})$. The concentration of hemoglobin in $10 \%$ hemolysate was determined by the cyanmethemoglobin method using Drabkin's reagent.

\section{Determination of uric acid, bilirubin, and albumin concentrations}

The serum concentrations of uric acid, albumin, and bilirubin were measured using PerkinElmer biochemical analyzer according to the manufacturer's instructions. Uric acid and bilirubin concentrations were expressed as $\mathrm{mg} / \mathrm{dl}$, while those for albumin were expressed as $\mathrm{g} / \mathrm{l}$.

\section{Determination of total thiols}

The concentration of thiol groups in serum was determined as described by Koster et al. (1986) using 5,5'-dithiobis(2-nitrobenzoic acid) (DTNB), which undergoes reduction by compounds containing sulfhydryl groups, yielding the yellow anion derivative, 5-thio-2-nitrobenzoate, which absorbs light at a wavelength of $412 \mathrm{~nm}$. This assay was carried out using an automated analyzer PerkinElmer. The results were expressed as $\mu$ mol per $g$ of protein $(\mathrm{P})$.

\section{Determination of total antioxidant capacity (TAC)}

Total antioxidant capacity was measured in serum according to Erel (2004). In this colorimetric method, radicals are generated and the antioxidant ability of seminal plasma reduces radical formation. The change in color of ABTS ions $\quad\left(2,2^{\prime}\right.$-azinobis(3-ethylbenzothiazoline-6-sulfonate) is measured as the change in absorbance at $660 \mathrm{~nm}$. This assay was conducted in an automated PerkinElmer analyzer calibrated with Trolox. Data were expressed as mmol/l.

\section{Determination of total oxidant status (TOS)}

Total oxidant status was measured in serum according to Erel (2005). The assay is based on the oxidation of ferrous ions to ferric ions in the presence of various oxidizing agents in acidic medium. The color change of xylenol orange by ferric ions is measured as the change in absorbance at $560 \mathrm{~nm}$. This assay was conducted in an automated analyzer (PerkinElmer) calibrated with hydrogen peroxide. Data were expressed as $\mu \mathrm{mol} / \mathrm{l}$.

\section{Oxidative stress index (OSI)}

The percentage ratio of TOS to TAC was used as an OSI.

\section{Determination of chemokines}

The levels of interleukin-8 (IL-8), eotaxin, interferon gamma-induced protein-10 (IP-10), MCP-1, macrophage inflammatory protein-1 $\beta$ (MIP-1 $\beta$ ), and RANTES were determined in serum using a Bio-Plex 200 System (BioRad Laboratories Inc., USA).

The Bio-Plex system is based on three core elements. The first core element is a technology that uses fluorescent magnetic microspheres (beads), each with a distinct color code to permit discrimination of individual tests within a multiplex suspension and allow the simultaneous 
detection of diverse analyte molecules in each single well of a 96-well microplate. Moreover, the magnetic beads allow for magnetic separation during the washing steps. The second core element is a specific flow cytometer with two lasers and associated optics to measure different molecules bound to the surface of the beads. The third core element is a high-speed digital signal processor that efficiently analyzes the fluorescent output.

The principle of these bead-based assays is similar to that of capture-sandwich immunoassays. The samples and standards were incubated with the antibody-coupled beads (antibodies directed against the desired cytokines were covalently coupled to internally dyed beads) in 96-well plates and washed. Next, the biotinylated detection antibodies specific for different cytokine epitopes were added. After incubation and washing, streptavidin (phycoerythrin solution) was added to bind to the biotinylated detection antibodies on the beads. The suspensions of the washed beads were analyzed using the Bio-Plex System. The software presented the data as both median fluorescence intensity and concentration $(\mathrm{pg} / \mathrm{ml})$.

\section{Statistical analysis}

The statistical analysis was performed using Statistica 9.1 PL software program. Data were expressed as mean \pm standard deviation (SD) for normally distributed data and in terms of median and interquartile range (IQR) for non-normally distributed data. Shapiro-Wilk's test was used to verify normality, and Levene's test was used to verify the homogeneity of variances. Statistical comparisons were made using $t$ test, $t$ test with separate variance estimates, Mann-Whitney $U$ test, or Chi-squared test. Dependent variables were analyzed using Student's $t$ test and Wilcoxon's test.

To compare the values of the measured cytokines in workers subchronically exposed to lead and those chronically exposed to lead, the levels of each cytokine in both groups were normalized. Values of cytokine levels measured in workers after subchronic exposure to lead were normalized to the median of the values obtained before exposure, while values of cytokine levels measured in chronically lead-exposed workers were normalized to the median of the values obtained from the control group.

Additionally, regression analysis was performed. The results of each parameter are not normally distributed. In order to obtain normal distributions, the values were logtransformed. However, we obtained a distribution, which enabled us to use multiple regression analyses only for IP-10, MIP-1 $\beta$, and IL-8. In multiple regression, we analyzed the effects of blood lead level, BMI, age, and smoking on IP-10, MIP-1 $\beta$, and IL-8 concentrations. Since cytokines concentrations differed significantly between the subchronically exposed group and the chronically exposed group, the group encoding the variable was introduced into the regression equation. A $p$ value $<0.05$ was considered to be significant.

\section{Results}

Epidemiologic data and blood lead concentrations are presented in Tables 1 and 2.

The levels of uric acid and bilirubin were significantly higher after a subchronic exposure to lead compared to the baseline by 22 and $35 \%$, respectively. Similarly, the values of TAC, TOS, and OSI increased by 15,50 , and $33 \%$, respectively. At the same time, the levels of thiol group and albumin decreased by 5 and $8 \%$, respectively (Table 3 ). The levels of IL- 8 and MIP-1 $\beta$ were significantly higher after a subchronic exposure to lead compared to the baseline by 34 and $20 \%$, respectively, while the levels of

Table 1 Epidemiologic data and lead exposure markers in the group of workers subchronically exposed to lead $(n=34)$

\begin{tabular}{lll}
\hline & Mean & SD \\
\hline Age (years) & 40 & 13 \\
Exposure duration (days) & 40 & 3 \\
Weight $(\mathrm{kg})$ & 79.3 & 12.5 \\
Height $(\mathrm{cm})$ & 176 & 6.71 \\
$\mathrm{Smokers}(\%)$ & $68 \%$ & - \\
$\mathrm{PbB}$ before exposure to lead $(\mu \mathrm{g} / \mathrm{dl})$ & 10.7 & 7.83 \\
$\mathrm{PbB}$ after exposure to lead $(\mu \mathrm{g} / \mathrm{dl})$ & 48.7 & 14.2 \\
$\mathrm{ZPP}(\mu \mathrm{g} / \mathrm{g} \mathrm{Hb})$ & 2.66 & 0.64 \\
\hline
\end{tabular}

$P b B$ blood lead level; $Z P P$ zinc protoporphyrin level in the blood

Table 2 Epidemiologic data and lead exposure markers in the group of workers chronically exposed to lead and in the control group

\begin{tabular}{|c|c|c|c|c|c|}
\hline & \multicolumn{2}{|c|}{$\begin{array}{l}\text { Chronic lead- } \\
\text { exposed group } \\
n=52\end{array}$} & \multicolumn{3}{|c|}{ Control group $n=22$} \\
\hline & Mean & SD & Mean & SD & $p$ \\
\hline Age (years) & 39 & 8 & 41 & 8 & 0.224 \\
\hline Years of work & 13 & 10 & 17 & 9 & 0.128 \\
\hline Height $(\mathrm{cm})$ & 177 & 5.58 & 179 & 8.03 & 0.112 \\
\hline Weight (kg) & 84.2 & 14.1 & 88.9 & 12.2 & 0.176 \\
\hline Smokers (\%) & $37 \%$ & - & $32 \%$ & - & $0.702^{*}$ \\
\hline $\mathrm{PbB}(\mu \mathrm{g} / \mathrm{dl})$ & 36.6 & 8.60 & 2.22 & 1.42 & $<0.001$ \\
\hline $\mathrm{ZPP}(\mu \mathrm{g} / \mathrm{g} \mathrm{Hb})$ & 4.24 & 1.82 & 2.38 & 0.61 & $<0.001$ \\
\hline
\end{tabular}

$P b B$ blood lead level; $Z P P$ zinc protoporphyrin level in the blood; $p$ value- $t$ test, $p^{*}$ value-Chi-squared test 
Table 3 Levels of uric acid, thiol groups, albumin, and bilirubin and values of total antioxidant capacity (TAC), total antioxidant status (TOS), and oxidative stress index (OSI) before and after subchronic exposure to lead, $p$ value- $t$ test for dependent variables, $p^{*}$ value-Wilcoxon's test

\begin{tabular}{|c|c|c|c|c|c|c|}
\hline & \multicolumn{2}{|c|}{ Before exposure } & \multicolumn{2}{|c|}{ After exposure } & \multirow{2}{*}{$\begin{array}{l}\text { Relative } \\
\text { change }(\%)\end{array}$} & \multirow[t]{2}{*}{$p$ value } \\
\hline & Mean & SD & Mean & SD & & \\
\hline Uric acid (mg/dl) & 6.23 & 1.00 & 7.57 & 1.88 & 22 & $<0.001$ \\
\hline Thiol groups $(\mu \mathrm{mol} / \mathrm{g} \mathrm{P})$ & 3.89 & 0.45 & 3.68 & 0.64 & -5 & 0.022 \\
\hline Albumin (g/l) & 6.62 & 0.93 & 6.07 & 1.05 & -8 & 0.013 \\
\hline Bilirubin (mg/dl) & 0.45 & 0.24 & 0.60 & 0.51 & 35 & $0.027 *$ \\
\hline $\mathrm{TAC}(\mathrm{mmol} / \mathrm{l})$ & 0.76 & 0.10 & 0.87 & 0.14 & 15 & $<0.001$ \\
\hline TOS $(\mu \mathrm{mol} / \mathrm{l})$ & 9.99 & 7.20 & 14.9 & 10.6 & 50 & $0.008 *$ \\
\hline OSI $(\%)$ & 1.35 & 0.98 & 1.79 & 1.32 & 33 & $0.022 *$ \\
\hline
\end{tabular}

Table 4 Levels of interleukin-8 (IL-8), eotaxin, interferon gammainduced protein-10 (IP-10), monocyte chemoattractant protein-1 (MCP-1), macrophage inflammatory protein-1 $\beta$ (MIP-1 $\beta$ ), and
RANTES (regulated on activation, normal $\mathrm{T}$ cell expressed and secreted) before and after subchronic exposure to lead showed as a median and interquartile range (IQR), $p$ value-Wilcoxon's test

\begin{tabular}{|c|c|c|c|c|c|c|}
\hline & \multicolumn{2}{|c|}{ Before exposure } & \multicolumn{2}{|c|}{ After exposure } & \multirow[t]{2}{*}{ Relative change (\%) } & \multirow[t]{2}{*}{$p$ value } \\
\hline & Median & IQR & Median & IQR & & \\
\hline IL-8 (pg/ml) & 4.30 & 3.53 & 5.77 & 6.37 & 34 & 0.047 \\
\hline Eotaxin $(\mathrm{pg} / \mathrm{ml})$ & 93.0 & 87.1 & 106 & 66.9 & 14 & 0.437 \\
\hline IP-10 (pg/ml) & 751 & 713 & 1052 & 795 & 40 & 0.074 \\
\hline MCP-1 (pg/ml) & 33.5 & 29.9 & 27.7 & 38.7 & -17 & 0.248 \\
\hline MIP-1 $\beta(\mathrm{pg} / \mathrm{ml})$ & 51.7 & 30.8 & 62.1 & 43.7 & 20 & 0.002 \\
\hline RANTES (pg/ml) & 21,431 & 3305 & 20,434 & 3309 & -5 & 0.174 \\
\hline
\end{tabular}

Table 5 Levels of interleukin-8 (IL-8), eotaxin, interferon gammainduced protein-10 (IP-10), monocyte chemoattractant protein-1 (MCP-1), macrophage inflammatory protein-1 $\beta$ (MIP-1 $\beta$ ), and RANTES (regulated on activation, normal $\mathrm{T}$ cell expressed and secreted) in the group of workers chronically exposed to lead and in the control group showed as a median and interquartile range (IQR), $p$ value-Mann-Whitney $U$ test

\begin{tabular}{|c|c|c|c|c|c|c|}
\hline & \multicolumn{2}{|c|}{ Control group } & \multicolumn{2}{|c|}{ Chronic lead-exposed group } & \multirow[t]{2}{*}{ Relative change (\%) } & \multirow[t]{2}{*}{$p$ value } \\
\hline & Median & IQR & Median & IQR & & \\
\hline IL-8 (pg/ml) & 2.11 & 0.50 & 2.95 & 0.90 & 40 & $<0.001$ \\
\hline Eotaxin $(\mathrm{pg} / \mathrm{ml})$ & 95.3 & 54.6 & 119 & 76.7 & 25 & 0.083 \\
\hline IP-10 (pg/ml) & 1237 & 676 & 887 & 552 & -28 & 0.036 \\
\hline MCP-1 (pg/ml) & 14.6 & 9.01 & 15.3 & 14.2 & 5 & 0.178 \\
\hline MIP-1 $\beta(\mathrm{pg} / \mathrm{ml})$ & 65.4 & 29.8 & 58.2 & 28.2 & -11 & 0.197 \\
\hline RANTES (pg/ml) & 21,607 & 1576 & 20,752 & 2059 & -4 & 0.109 \\
\hline
\end{tabular}

eotaxin, IP-10, MCP-1, and RANTES did not change after a subchronic exposure to lead (Table 4).

The level of IL- 8 was significantly higher in the group of workers chronically exposed to lead than in the control group by $40 \%$, while the level of IP-10 was significantly lower by $28 \%$. The levels of the remaining chemokines did not differ between both groups (Table 5).

Multiple regression analysis showed that the duration of lead exposure (subchronic vs. chronic) affects IP-10 and MIP-1 $\beta$ concentrations. Besides, the BMI, age, and smoking habits did not significantly affect the levels of those cytokines. In consistence with these results, comparisons made between the medians of the normalized cytokine levels in subchronically and chronically lead-exposed groups showed significant differences in the normalized values of IP-10, MCP-1, and MIP-1 $\beta$ levels between the two groups (Table 6).

\section{Discussion}

Results of the present study showed that subchronic exposure to lead is able to increase uric acid level in the blood. However, increased uric acid level may be not only due 
Table 6 Normalized cytokine levels obtained from subchronically and chronically lead-exposed groups showed as a median and interquartile range (IQR), $p$ value-Mann-Whitney $U$ test

\begin{tabular}{|c|c|c|c|c|c|}
\hline & \multicolumn{2}{|c|}{$\begin{array}{l}\text { Subchronic } \\
\text { exposure } N=34\end{array}$} & \multicolumn{2}{|c|}{$\begin{array}{l}\text { Chronic exposure } \\
N=52\end{array}$} & \multirow[t]{2}{*}{$p$ value } \\
\hline & Median $^{\mathrm{a}}$ & IQR & Median $^{\mathrm{b}}$ & IQR & \\
\hline IL-8 (\%) & 134 & 80-229 & 140 & 114-157 & 0.980 \\
\hline Eotaxin $(\%)$ & 114 & $66-138$ & 125 & $87-168$ & 0.180 \\
\hline IP-10 (\%) & 140 & 83-189 & 72 & $55-100$ & $<0.001$ \\
\hline MCP-1 (\%) & 83 & $32-148$ & 105 & 79-176 & 0.007 \\
\hline MIP-1 $\beta(\%)$ & 120 & 96-181 & 89 & 70-114 & $<0.001$ \\
\hline RANTES (\%) & 95 & 95-101 & 96 & 91-101 & 0.660 \\
\hline
\end{tabular}

a Median of the values of cytokine levels measured in workers after subchronic exposure to lead that were normalized to the median of the values obtained before exposure

b Median of the values of cytokine levels measured in chronically lead-exposed workers that were normalized to the median of the values obtained from the control group

to the subclinical renal function impairment but also due to altered purine metabolism. In our previous study, we showed a positive association between lead exposure and the activity of xanthine oxidase, which is responsible for uric acid formation from purines being degraded (Kasperczyk et al. 2013). In consistence with these results, positive correlations between blood lead levels and uric acid concentrations were observed by Hernández-Serrato et al. (2006) in subjects environmentally exposed to high doses of lead and by Wang et al. (2002) and Ehrlich et al. (1998) in battery factory workers. Besides, Khan et al. (2008) reported an increased uric acid level in a group of chronically lead-exposed workers $(\mathrm{PbB}=29.1 \mu \mathrm{g} / \mathrm{dl})$. Similarly, a study on workers chronically exposed to high doses of lead reported same results $(\mathrm{PbB}=80.9 \mu \mathrm{g} / \mathrm{dl})$. However, there are human studies showing no association between lead exposure and uric acid levels (Konishi et al. 1994; Roels et al. 1994).

Uric acid acts as a scavenger of ROS and serves as a main antioxidant in human plasma (Gersch et al. 2008). Therefore, the elevation of uric acid level may compensate for the simultaneous decrease in thiol group level. As a result, the TAC value was paradoxically increased due to subchronic lead exposure. However, uric acid has also been shown to act as a pro-oxidant. Uric acid is able to react directly with nitric oxide (NO) to form 6-aminouracil. This irreversible reaction, resulting in depletion of $\mathrm{NO}$, can be partially blocked by glutathione (GSH). Therefore, under oxidative stress conditions, when the GSH pool is depleted, uric acid may induce endothelial dysfunction (Gersch et al. 2008; Xie et al. 2015). It is well documented that lead exposure induces GSH depletion (Kasperczyk et al. 2014). In light of this, the role of uric acid in the defense against lead toxicity can be divergent and may depend on the specific redox conditions of the particular microenvironment. What makes this issue more complicated is that uric acid also exerts pro-inflammatory properties (Hayden and Tyagi 2004).

In in vitro studies, both lead and uric acid have been reported to induce the expression of IL-8 via MAPKs and NF- $\mathrm{BB}$ signaling pathways (Lin et al. 2015; Liang et al. 2015). IL-8 is secreted by multiple cell types in response to pro-inflammatory stimuli and serves as a strong chemotactic agent for neutrophils. Neutrophils may cause oxidative damage to tissues. Consequently, IL- 8 may be involved in many inflammatory diseases, such as rheumatoid arthritis, gouty arthritis, asthma, and acute respiratory distress syndrome. Besides, experimental studies showed that IL-8 plays a role in promotion of angiogenesis and metastasis (Lin et al. 2015; Yan et al. 2015). Since this study showed elevated level of IL-8 due to both subchronic and chronic lead exposure, then IL-8 may also display negative effects in humans exposed to lead toxicity.

Similarly, MCP-1 expression and level have been shown to be increased by lead and uric acid through MAPKs and NF- $\mathrm{BB}$ signaling pathways in in vitro and experimental studies (Kanellis et al. 2003; Kumawat et al. 2014; Liang et al. 2015; Soliman et al. 2015; Zhou et al. 2012). In addition, uric acid has been reported to increase the expression and levels of RANTES in vitro (Zhou et al. 2012). MCP-1 is released due to pro-inflammatory stimuli and displays a chemoattractive activity on monocytes, basophils, and lymphocytes, thus plays a role in the allergic reactions (Luster and Rothenberg 1997). RANTES also belongs to the chemokine family and is responsible for recruiting a variety of leukocytes into the inflammation sites, such as lymphocytes, macrophages, eosinophils, and basophils (Aldinucci and Colombatti 2014). Levels of both MCP-1 and RANTES were not significantly affected by subchronic and chronic exposure to lead. However, a comparison made between the normalized values of MCP-1 in subchronically and chronically lead-exposed workers showed that the influence of lead on MCP-1 level might be opposite depending on the exposure period.

As in the case of MCP-1 and RANTES, the present study did not confirm the influence of lead exposure on eotaxin level. Eotaxin acts as a chemokine-stimulating eosinophils chemotaxis. Besides, eotaxin induces the release of eosinophils from the bone marrow, their aggregation, and their respiratory burst activity (Rankin et al. 2000).

Results of the present study indicated that a subchronic exposure to lead, apart from increasing the level of IL-8, might induce inflammation via increasing the level of MIP- $1 \beta$, a member of the MIP-1 family, which orchestrates acute and chronic inflammatory host responses by recruiting pro-inflammatory cells, especially lymphocytes 
and monocytes (Maurer and von Stebut 2004). Chronic exposure to lead did not significantly affect the level of MIP-1 $\beta$ but influenced the level of IP-10, which serves as a chemokine as well. The level of IP-10 was significantly lower in chronically lead-exposed workers than in the control group. The secretion of IP-10 by lymphocytes depends on IFN- $\gamma$ level and is related to the Th1-mediated immune response (Antonelli et al. 2014). Therefore, a decrease in IP-10 level due to chronic lead exposure may be caused by lead-induced skewing toward the Th2-mediated immune response as postulated in some experimental studies (Heo et al. 2007; 1996; Hsiao et al. 2011). Besides, it has been postulated that uric acid is also able to trigger the Th2mediated immune response (Moon et al. 2010). Additionally, multiple regression analysis and comparisons made between the normalized values of IP-10 and MIP- $1 \beta$ in subchronically and chronically lead-exposed workers confirmed that the influence of lead on their levels is divergent in those two different types of exposures. Iavicoli et al. (2006) showed that the effect of lead exposure on cytokine levels in mice depends on the blood lead level. However, results of the present study indicate that lead may affect cytokine levels in different ways depending on the exposure duration rather than blood lead level.

In our previous study on chronically lead-exposed workers, we reported not only a higher level of uric acid but also a higher bilirubin level. In addition, the present study showed an increased level of bilirubin due to subchronic exposure to lead. Bilirubin is the end product of heme degradation. Heme is converted by heme oxygenase (HO) to biliverdin, which is in turn reduced to bilirubin by biliverdin reductase. Bilirubin has been shown to have a strong antioxidant potential against peroxyl radicals; however, it could also exert toxic effects when present in excess (Fuhua et al. 2012; Annabi Berrahal et al. 2007). Several animal studies on rats showed elevated bilirubin levels as a result of lead exposure (Abdel-Moneim et al. 2011; Annabi Berrahal et al. 2007; Ibrahim et al. 2011). Such elevation of bilirubin level may be beneficial owing to its antioxidant properties. In accordance with this, Noriega et al. (2003) showed that bilirubin administration to rats increased GSH level, enhanced the activity of antioxidant enzymes, and decreased the toxicity induced by $\delta$-aminolevulinic acid (ALA). ALA accumulates because of the lead-induced inhibition of $\delta$-aminolevulinic acid dehydratase (ALAD) (Wang et al. 2015). Therefore, high bilirubin level may contribute to the elevation of the TAC value. On the other hand, results of human studies on the role of bilirubin in lead toxicity are not as conclusive as those of the experimental studies. Al-Neamy et al. (2001) and Khan et al. (2008) did not report any significant association between bilirubin level and chronic lead exposure in male workers. The negative results of these studies may be due to the complexity of the possible interactions between lead and heme metabolism. On the one hand, it is well documented that lead inhibits heme biosynthesis (Dobrakowski et al. 2014). Consequently, the depletion of the heme pool may result in its decreased degradation and less bilirubin synthesis. On the other hand, lead may induce heme degradation via induction of the inducible isoform of heme oxygenase (HO-1) (Vargas et al. 2003). Lead may also increase heme degradation via induction of eryptosis (Aguilar-Dorado et al. 2014).

In contrast to uric acid and bilirubin levels, the level of albumin significantly decreased after a subchronic exposure to lead compared to the baseline. Similarly, in our previous study, we reported lower albumin level in chronically lead-exposed workers when compared to the control group. In consistence with our results, Khan et al. (2008) reported decreased serum albumin and total protein levels in lead-exposed industrial workers. Koo et al. (1994) reported decreased albumin mRNA level in rat liver due to lead nitrate administration. This experimental study further supports the results of the human studies.

Albumin is the most abundant plasma protein, which serves to buffer the blood, maintain the osmotic pressure, and as a carrier of many compounds (Guo et al. 2014). Because of their ROS scavenging activity, thiol groups of cysteine residues of albumin determine the plasma redox status (Dobrakowski et al. 2014). Therefore, decreased level of thiol groups, observed in the present study may be secondary to the decrease in albumin level. The second possible explanation for the reduced thiol group level is the well-documented high affinity of lead toward thiol groups (Dobrakowski et al. 2014). In accordance with the human studies, decreased level of thiol groups was also reported in experimental studies in rats (El-Missiry 2000; Tandon et al. 2002). Our previous study on chronically lead-exposed workers also showed decreased thiol group level (Dobrakowski et al. 2014). Interactions between lead and thiol groups may also influence the immune response because it has been proposed that lead may affect lymphocyte functions due to its high affinity for the sulfhydryl groups on T-lymphocyte surface receptors. As a result, antigen processing from monocytes to $\mathrm{T}$ lymphocytes may be impaired (García-Lestón et al. 2012).

The development of oxidative stress in chronic lead exposure is well established (Kasperczyk et al. 2014). The decrease in thiol group level and the elevation of TOS and OSI values observed in the present study confirm that a subchronic exposure to lead is also able to induce oxidative stress despite increased TAC value.

The results of this study need to be evaluated within the context of its limitations. A major limitation was a limited groups' size. Besides, the possible confounding role of other pollutants was not taken into consideration. 


\section{Conclusions}

Similar to chronic lead exposure, subchronic exposure to lead modifies the blood levels of uric acid, thiol groups, bilirubin, and albumin in humans. Modifications of uric acid and bilirubin levels may be related to the non-enzymatic antioxidant defense mechanisms against lead toxicity and result in increased TAC value. However, this elevation seems to be insufficient to protect against lipid peroxidation and to compensate for thiol depletion. In both subchronic and chronic lead exposures, oxidative stress may be enhanced by the pro-inflammatory action of chemokines, especially IL-8. Besides, lead may affect IP-10, MCP1 , and MIP-1 $\beta$ levels in different ways depending on the exposure duration rather than blood lead level. These results indicate a need to investigate the mechanisms of human adaptation to lead toxicity related to the exposure period.

\section{Compliance with ethical standards}

Conflict of interest The authors declare that they have no conflict of interest.

Open Access This article is distributed under the terms of the Creative Commons Attribution 4.0 International License (http://creativecommons.org/licenses/by/4.0/), which permits unrestricted use, distribution, and reproduction in any medium, provided you give appropriate credit to the original author(s) and the source, provide a link to the Creative Commons license, and indicate if changes were made.

\section{References}

Abdel-Moneim AE, Dkhil MA, Al-Quraishy S (2011) The redox status in rats treated with flaxseed oil and lead-induced hepatotoxicity. Biol Trace Elem Res 143:457-467

Aguilar-Dorado IC, Hernández G, Quintanar-Escorza MA, Maldonado-Vega M, Rosas-Flores M, Calderón-Salinas JV (2014) Eryptosis in lead-exposed workers. Toxicol Appl Pharmacol 281:195-202. doi:10.1016/j.taap.2014.10.003

Aldinucci D, Colombatti A (2014) The inflammatory chemokine CCL5 and cancer progression. Mediators Inflamm 2014:292376. doi: $10.1155 / 2014 / 292376$

Al-Neamy FR, Almehdi AM, Alwash R, Pasha MA, Ibrahim A, Bener A (2001) Occupational lead exposure and amino acid profiles and liver function tests in industrial workers. Int J Environ Health Res 11:181-188

Alya A, Ines DB, Montassar L, Najoua G, el Saloua F (2015) Oxidative stress, biochemical alterations, and hyperlipidemia in female rats induced by lead chronic toxicity during puberty and post puberty periods. Iran J Basic Med Sci 18:1034-1043

Annabi Berrahal A, Nehdi A, Hajjaji N, Gharbi N, El-Fazâa S (2007) Antioxidant enzymes activities and bilirubin level in adult rat treated with lead. C R Biol 330:581-588

Antonelli A, Ferrari SM, Giuggioli D, Ferrannini E, Ferri C, Fallahi P (2014) Chemokine (C-X-C motif) ligand (CXCL) 10 in autoimmune diseases. Autoimmun Rev 13:272-280. doi:10.1016/j.autrev.2013.10.010

Dobrakowski M, Zalejska-Fiolka J, Wielkoszyński T, Świętochowska E, Kasperczyk S (2014) The effect of occupational exposure to lead on the non-enzymatic antioxidant system. Med Pr 65:443-451

Ehrlich R, Robins T, Jordaan E, Miller S, Mbuli S, Selby P, Wynchank S, Cantrell A, De Broe M, D'Haese P, Todd A, Landrigan P (1998) Lead absorption and renal dysfunction in a South African battery factory. Occup Environ Med 55:453-460

El-Missiry MA (2000) Prophylactic effect of melatonin on leadinduced inhibition of heme biosynthesis and deterioration of antioxidant systems in male rats. J Biochem Mol Toxicol $14: 57-62$

Erel O (2004) A novel automated direct measurement method for total antioxidant capacity using a new generation, more stable ABTS radical cation. Clin Biochem 37:277-285

Erel O (2005) A new automated colorimetric method for measuring total oxidant status. Clin Biochem 38:1103-1111

Fuhua P, Xuhui D, Zhiyang Z, Ying J, Yu Y, Feng T, Jia L, Lijia G, Xueqiang H (2012) Antioxidant status of bilirubin and uric acid in patients with myasthenia gravis. NeuroImmunoModulation 19:43-49

García-Lestón J, Roma-Torres J, Mayan O, Schroecksnadel S, Fuchs D, Moreira AO, Pásaro E, Méndez J, Teixeira JP, Laffon B (2012) Assessment of immunotoxicity parameters in individuals occupationally exposed to lead. J Toxicol Environ Health A 75:807-818

Gersch C, Palii SP, Kim KM, Angerhofer A, Johnson RJ, Henderson GN (2008) Inactivation of nitric oxide by uric acid. Nucleosides, Nucleotides Nucleic Acids 27:967-978. doi:10.1080/15257770802257952

Guo M, He L, Strong PJ, Wang H (2014) Binding between lead ions and the high-abundance serum proteins. Chemosphere 112:472480. doi:10.1016/j.chemosphere.2014.05.018

Hayden MR, Tyagi SC (2004) Uric acid: a new look at an old risk marker for cardiovascular disease, metabolic syndrome, and type 2 diabetes mellitus: the urate redox shuttle. Nutr Metab (Lond) $1: 10$

Heo Y, Parsons PJ, Lawrence DA (1996) Lead differentially modifies cytokine production in vitro and in vivo. Toxicol Appl Pharmacol 138:149-157

Heo Y, Mondal TK, Gao D, Kasten-Jolly J, Kishikawa H, Lawrence DA (2007) Posttranscriptional inhibition of interferon-gamma production by lead. Toxicol Sci 96:92-100

Hernández-Serrato MI, Fortoul TI, Rojas-Martínez R, Mendoza-Alvarado LR, Canales-Treviño L, Bochichio-Riccardelli T, AvilaCosta MR, Olaiz-Fernández G (2006) Lead blood concentrations and renal function evaluation: study in an exposed Mexican population. Environ Res 100:227-231

Hsiao CL, Wu KH, Wan KS (2011) Effects of environmental lead exposure on T-helper cell-specific cytokines in children. J Immunotoxicol 8:284-287

Iavicoli I, Carelli G, Stanek EJ 3rd, Castellino N, Calabrese EJ (2006) Below background levels of blood lead impact cytokine levels in male and female mice. Toxicol Appl Pharmacol 210:94-99

Ibrahim NM, Eweis EA, El-Beltagi HS, Abdel-Mobdy YE (2011) The effect of lead acetate toxicity on experimental male albino rat. Biol Trace Elem Res 144:1120-1132. doi:10.1007/s12011-011-9149-Z

Kanellis J, Watanabe S, Li JH, Kang DH, Li P, Nakagawa T, Wamsley A, Sheikh-Hamad D, Lan HY, Feng L, Johnson RJ (2003) Uric acid stimulates monocyte chemoattractant protein-1 production in vascular smooth muscle cells via mitogen-activated protein kinase and cyclooxygenase-2. Hypertension 41:1287-1293

Kasperczyk S, Dobrakowski M, Ostałowska A, Kasperczyk A, Wilczyiński S, Wyparło-Wszelaki M, Kiełtucki J, Birkner E 
(2013) Lead-elevated activity of xanthine oxidase in leadexposed workers. Med Pr 64:175-180

Kasperczyk S, Dobrakowski M, Kasperczyk J, Ostałowska A, Zalejska-Fiolka J, Birkner E (2014) Beta-carotene reduces oxidative stress, improves glutathione metabolism and modifies antioxidant defense systems in lead-exposed workers. Toxicol Appl Pharmacol 280:36-41. doi:10.1016/j.taap.2014.07.006

Khan DA, Qayyum S, Saleem S, Khan FA (2008) Lead-induced oxidative stress adversely affects health of the occupational workers. Toxicol Ind Health 24:611-618

Konishi Y, Endo G, Kiyota A, Horiguchi S (1994) Fractional clearances of low molecular weight proteins in lead workers. Ind Health 32:119-127

Koo P, Nagai MK, Farber E (1994) Multiple sites of control of glutathione S-transferase P1-1 in rat liver. J Biol Chem 269:14601-14606

Koster JF, Biemond P, Swaak AJ (1986) Intracellular and extracellular sulphydryl levels in rheumatoid arthritis. Ann Rheum Dis 45:44-46

Kumawat KL, Kaushik DK, Goswami P, Basu A (2014) Acute exposure to lead acetate activates microglia and induces subsequent bystander neuronal death via caspase-3 activation. Neurotoxicology 41:143-153. doi:10.1016/j.neuro.2014.02.002

Liang WY, Zhu XY, Zhang JW, Feng XR, Wang YC, Liu ML (2015) Uric acid promotes chemokine and adhesion molecule production in vascular endothelium via nuclear factor-kappa B signaling. Nutr Metab Cardiovasc Dis 25:187-194. doi:10.1016/j. numecd.2014.08.006

Lin YC, Wei PL, Tsai YT, Wong JH, Chang CM, Wang JY, Hou MF, Lee YC, Chuang HY, Chang WC (2015) $\mathrm{Pb}^{2+}$ induced IL-8 gene expression by extracellular signal-regulated kinases and the transcription factor, activator protein 1, in human gastric carcinoma cells. Environ Toxicol 30:315-322. doi:10.1002/tox.21909

Liu CM, Sun YZ, Sun JM, Ma JQ, Cheng C (2012) Protective role of quercetin against lead-induced inflammatory response in rat kidney through the ROS-mediated MAPKs and NF-кB pathway. Biochim Biophys Acta 1820:1693-1703. doi:10.1016/j. bbagen.2012.06.011

Luster AD, Rothenberg ME (1997) Role of the monocyte chemoattractant protein and eotaxin subfamily of chemokines in allergic inflammation. J Leukoc Biol 62:620-633

Maurer M, von Stebut E (2004) Macrophage inflammatory protein-1. Int J Biochem Cell Biol 36:1882-1886

Moon HG, Tae YM, Kim YS, Gyu Jeon S, Oh SY, Song Gho Y, Zhu Z, Kim YK (2010) Conversion of Th17-type into Th2type inflammation by acetyl salicylic acid via the adenosine and uric acid pathway in the lung. Allergy 65:1093-1103. doi:10.1111/j.1398-9995.2010.02352.x
Noriega GO, Tomaro ML, del Batlle AM (2003) Bilirubin is highly effective in preventing in vivo delta-aminolevulinic acid-induced oxidative cell damage. Biochim Biophys Acta 1638:173-178

Rankin SM, Conroy DM, Williams TJ (2000) Eotaxin and eosinophil recruitment: implications for human disease. Mol Med Today 6:20-27

Roels H, Lauwerys R, Konings J, Buchet JP, Bernard A, Green S, Bradley D, Morgan W, Chettle D (1994) Renal function and hyperfiltration capacity in lead smelter workers with high bone lead. Occup Environ Med 51:505-512

Soliman MM, Baiomy AA, Yassin MH (2015) Molecular and histopathological study on the ameliorative effects of curcumin against lead acetate-induced hepatotoxicity and nephrotoxicity in wistar rats. Biol Trace Elem Res 167:91-102. doi:10.1007/ s12011-015-0280-0

Tandon SK, Prasad S, Singh S, Shukla M, Chatterjee M (2002) Influence of age on lead-induced oxidative stress in rat. Biol Trace Elem Res 88:59-69

Vargas H, Castillo C, Posadas F, Escalante B (2003) Acute lead exposure induces renal heme oxygenase- 1 and decreases urinary $\mathrm{Na}+$ excretion. Hum Exp Toxicol 22:237-244

Wang VS, Lee MT, Chiou JY, Guu CF, Wu CC, Wu TN, Lai JS (2002) Relationship between blood lead levels and renal function in lead battery workers. Int Arch Occup Environ Health 75:569-575

Wang J, Yang Z, Lin L, Zhao Z, Liu Z, Liu X (2012) Protective effect of naringenin against lead-induced oxidative stress in rats. Biol Trace Elem Res 146:354-359. doi:10.1007/s12011-011-9268-6

Wang X, Wang L, Liu S (2015) Heme-regulated eIF2 $\alpha$ kinase plays a crucial role in protecting erythroid cells against lead-induced hemolytic stress. Chem Res Toxicol 28:460-469. doi:10.1021/ tx500422q

Xie H, Sun J, Chen Y, Zong M, Li S, Wang Y (2015) EGCG attenuates uric acid-induced inflammatory and oxidative stress responses by medicating the NOTCH pathway. Oxid Med Cell Longev 2015:214836. doi: $10.1155 / 2015 / 214836$

Yan Z, Wang J, Li J, Jiang N, Zhang R, Yang W, Yao W, Wu W (2015) Oxidative stress and endocytosis are involved in upregulation of interleukin-8 expression in airway cells exposed to PM2.5. Environ Toxicol. doi:10.1002/tox.22188 [Epub ahead of print]

Yang Y, Zhang X, Fu Y, Yang H (2014) Leptin and IL-8: two novel cytokines screened out in childhood lead exposure. Toxicol Lett 227:172-178

Zhou Y, Fang L, Jiang L, Wen P, Cao H, He W, Dai C, Yang J (2012) Uric acid induces renal inflammation via activating tubular NF-кB signaling pathway. PLoS ONE 7:e39738. doi:10.1371/ journal.pone.0039738 